\title{
The potential for using treated petroleum drill cuttings in mine backfill
}

\author{
M. S. Awopetu ${ }^{1}$, S. O. Awopetu ${ }^{2} \&$ J. Stegemann ${ }^{3}$ \\ ${ }^{1}$ Department of Civil Engineering, University of Ibadan, Nigeria \\ ${ }^{2}$ Nigeria National Petroleum Commission (NNPC) Nigeria \\ ${ }^{3}$ Department of Environmental, Civil and Geomatic Engineering, \\ University College, UK
}

\begin{abstract}
The oil and gas industry generates huge quantities of petroleum drill cuttings (PDC) while exploring for hydrocarbon resources. These wastes are usually contaminated; for this reason, environmental legislation prohibits their disposal without treatment. The mining industry similarly exploits the earth for valuable minerals and creates cavities in the process. These cavities are currently supported and filled with cement paste backfill, (CPB) made from mine tailings during and after mining activities. The increasing cost of mining operations arising from the cost of CPB and the need to effectively dispose of treated PDC suggests a possible industrial synergy could be achieved between the two industries; utilising the waste of one (PDC from oil exploration) in the production chain of the other (CPB for mine backfill). This work investigated the potential for use of PDC treated by thermal desorption as a mine backfill material. Extensive literature analysis was done on the various methods available for treatment of PDC. Various potential and current utilisations of PDC and their environmental impacts were also discussed. The research outcome showed the possibility of use of thermally treated PDC waste as mine backfill material for general fill (Post operations) rather than ground support or free-standing fill applications.
\end{abstract}

Keywords: petroleum drill cuttings, potential, cement paste backfill, exploration, hydrocarbon resources, environmental. 


\section{Introduction}

Petroleum drill-cuttings (PDC) are wastes that are unavoidably produced in the course of drilling wells towards oil and gas production. They are generated in large quantities on every drilling operation both offshore and onshore. PDC are by-product of the drilling process usually contaminated with residual drilling muds. They are primarily made up of shale, quartz, sand and limestone [1]. In most operations, general physical observation indicates that PDC are granular, variable and hazardous in nature owing to the mud content that accompany their production [2]. The process of drilling a well requires the use of drilling muds also referred to as drilling fluids [3]. This is done to prevent clogging of the well being drilled and to facilitate transportation PDC from the subsurface to the earth surface. In addition to these functions, they act as lubricant and coolant, suppress formation fluid pressure, stabilise walls of the borehole, reduce drill pipe corrosion and act as a medium for obtaining information on the well being drilled.

PDC generated while drilling returns to the surface with the circulating drilling muds, where a primary physical separation is carried out before they transferred into the waste pit [3]. Physical separation is however not sufficient because the wastes remain contaminated with trace of drilling muds. This is responsible for its classification as hazardous wastes [4]. Until recently, the bulk of PDC produced are disposed directly into the seabed and landfill without further treatment resulting into serious negative ecological and environmental impacts $[3,5]$. This poses a serious environmental challenge to the oil and gas industry owing to the large quantities generated coupled with their content of organic and inorganic contaminants.

A cursory look at the typical treatment processes for PDC, such as thermal desorption, solvent extraction, and stabilisation/solidification show a lack of holism in the cradle to grave handling of the waste because all the treatments still require disposal of a residue. Most of these treatment processes have high carbon footprint and could be expensive. In order to compensate for the cost of treatment and the impact of increased waste generation in form of residue, there is need to consider ways of effectively utilising treated PDC. This brings us to the next phase of waste management hierarchy of recycling. It involves processing waste into new products by preventing disposal of useful materials, reduction in consumption of fresh raw materials and energy resources. Recycling of PDC waste is an emerging field and has very little application to date. A few literatures have indicated various potential utilisation of PDC with minimal applications. For instance, the ability of untreated PDC as an aggregate in concrete showed that workability and strength of mix was reduced by up to $20 \%$ when compared to normal concrete [6].

Furthermore, in an increasingly challenging world of economic meltdown, climate change, and concerns about energy and food security, the need for partnership among industries is highly desirable. This partnership permeates down the value chain leading to savings in the consumption of limited natural resources through the utilisation of one sector's waste in the production chain of 
the other. An example is the mining industry, which creates cavities in the earth while extracting valuable minerals. These cavities must be backfilled while the oil industry generates large quantity of PDC from the boreholes during drilling and do not require any form of backfill for its operations. Presently, CPB, an engineered mixture of tailings ( $75-85 \%$ solid by weight), a hydraulic binder (3$7 \%$ by dry total paste weight) and water is used to fill these cavities in the mining industry [7]. The primary purpose of using CPB is to ensure and maintain safe underground mining activities in an economic and environmentally sustainable way [8]. This work seeks to investigate the potential for use of PDC treated by thermal desorption as a mine backfill material.

\section{Method}

To achieve the objective stated above, 10kg of PDC contaminated with OBM were obtained from the North Sea. The samples were obtained at depths 10,560ft and 11,330ft beneath the earth from the same well. These samples were kept at room temperature in air-tight packs in the UCL Environmental laboratory. The PDC is to be subjected to thermal treatment in the muffle furnace in batches. This treatment is similar to thermal desorption process that is currently deployed in the treatment of PDC from North Sea. The optimum treatment temperature is also to be determined in addition to weighing of the samples before and after treatment to find out weight loss of Oil Based Mud (OBM) content.

Afterwards, the samples are used to make backfill cubes and cylinders according to the standard CPB procedure. Various fresh and hard backfill tests are carried out in line with industrial requirement. The cubes backfill samples are tested in triplicates to determine the rate of strength development on 3, 7, 14, 28 and 56 curing ages. The cylinder samples are also used to estimate the hydraulic conductivity of the PDC backfill. These results are then compared with the standard backfill requirements and discussed. In addition to these, extensive literature review on the various environmental impacts and potential utilisation of PDC is to be analysed.

\subsection{Background information on PDC samples and OPC}

Two sets of 5kg OBM generated PDC samples were obtained from the North Sea through British Petroleum (BP). The samples were carefully packaged $(1 \mathrm{~kg}$ each) in 10 air tight containers to retain its freshness and pristine state. The two samples were taken from the same well drilling operation but at different depths of $10,560 \mathrm{ft}$ and $11,330 \mathrm{ft}$. The samples were semi-solid in texture and OBM contaminated. Very little information was available on the initial characteristics of the PDC. However, a mud report showing mud composition and depths where samples were collected was supplied by BP. These samples were stored in a refrigerator in the laboratory to maintain their state before use. Ordinary Portland cement (OPC), CEM I 52.5 conforming to BS EN 197-1:2000, was used. The material was packaged in an air-tight container in the laboratory. 


\subsection{Test procedure}

Various tests were conducted on each of OPC-B and PFA-B samples in accordance with the standard mine backfill preparation described by Belem and Benzaazoua [9]. All hardened tests carried out were done in triplicate at 3, 7, 14, 21,28 and 56 days curing ages except for the hydraulic conductivity test that was done in duplicate at only 28days curing age. The tests carried out on both fresh and hard backfill mixes (OPC-B and PFA-B) are listed below:

- Flow table test (to determine the consistency of the mixes)

- Determination of bulk density (through measurement of samples' mass and volume)

- Moisture content and specific gravity of crushed wet and dried samples (to determine the porosity of backfill)

- UCS according to BS EN 19661: 2005 (to determine the rate of strength development of backfill mixes

- Hydraulic Conductivity test according to ASTM D5084603 method $\mathrm{D}$ ( to determine the porosity of solid backfill mixes)

\section{Results}

Table 1: $\quad$ Flow table test results.

\begin{tabular}{|c|c|c|c|}
\hline Samples & $\left.\mathbf{d}_{\mathbf{1}} \mathbf{( m m}\right)$ & $\left.\mathbf{d}_{\mathbf{2}} \mathbf{( m m}\right)$ & $\mathbf{f}(\mathbf{m m})$ \\
\hline OPC Backfill & 260 & 260 & 260 \\
\hline PFA Backfill & 210 & 220 & 215 \\
\hline
\end{tabular}

where: $d_{1}=$ first flow diameter;

$\mathrm{d}_{2}=$ second flow diameter; and

$\mathrm{f}=$ flow diameter $\left[\left(\mathrm{d}_{1}+\mathrm{d}_{2}\right) / 2\right]$.

Table 2: Relationship between bulk density and curing age of backfill samples.

\begin{tabular}{|c|c|c|c|c|c|c|}
\hline \multirow[b]{2}{*}{$\begin{array}{c}\text { Curing } \\
\text { Age } \\
\text { (days) }\end{array}$} & \multicolumn{3}{|c|}{ OPC-B Cubes } & \multicolumn{3}{|c|}{ PFA-B Cubes } \\
\hline & $\begin{array}{l}\text { Volume } \\
\left(\mathrm{cm}^{3}\right)\end{array}$ & $\begin{array}{c}\text { Mass } \\
\text { (g) }\end{array}$ & $\begin{array}{c}\text { Bulk } \\
\text { Density } \\
\text { (g/cm3) }\end{array}$ & $\begin{array}{c}\text { Volume } \\
\left(\mathrm{cm}^{3}\right)\end{array}$ & $\begin{array}{c}\text { Mass } \\
(\mathrm{g})\end{array}$ & $\begin{array}{c}\text { Bulk } \\
\text { Density } \\
(\mathrm{g} / \mathrm{cm} 3)\end{array}$ \\
\hline 3 & 121.49 & 185.67 & 1.53 & 121.49 & 215.00 & 1.77 \\
\hline 7 & 123.00 & 205.00 & 1.67 & 128.95 & 217.33 & 1.69 \\
\hline 14 & 127.64 & 205.50 & 1.61 & 129.92 & 216.00 & 1.66 \\
\hline 21 & 123.87 & 204.25 & 1.65 & 126.74 & 212.50 & 1.68 \\
\hline 28 & 123.01 & 207.00 & 1.68 & 125.72 & 210.00 & 1.67 \\
\hline 56 & 127.51 & 202.00 & 1.58 & 125.93 & 206.50 & 1.64 \\
\hline
\end{tabular}

\subsection{Compressive strength test results}

Samples were tested in triplicates for each curing age of 3, 7, 14, 21, 28 and 56 days to ensure repetitiveness and accuracy of results. The results obtained in 
each case are averaged and values recorded as shown in Tables 3 and 4 for OPC$\mathrm{B}$ and PFA-B samples respectively. Graphical representations of these results are also presented in Figures 2, 3, 4 and 5.

Table 3: OPC-B samples compressive strength results at various curing ages.

\begin{tabular}{|c|c|c|c|}
\hline Curing Age (days) & $\mathbf{F}(\mathbf{N})$ & $\mathbf{A}_{\mathbf{c}}\left(\mathbf{m m}^{\mathbf{2}}\right)$ & $\boldsymbol{f}_{\boldsymbol{c}} \mathbf{( \mathbf { N }} / \mathbf{m m}^{\mathbf{2}} \mathbf{)}$ \\
\hline 3 & 300 & 2500 & 0.12 \\
\hline 7 & 600 & 2500 & 0.24 \\
\hline 14 & 750 & 2500 & 0.30 \\
\hline 21 & 800 & 2525 & 0.32 \\
\hline 28 & 1400 & 2550 & 0.55 \\
\hline 56 & 1450 & 2500 & 0.58 \\
\hline
\end{tabular}

Table 4: $\quad$ PFA-B samples compressive strength results at various curing ages.

\begin{tabular}{|c|c|c|c|}
\hline Curing Age (days) & $\mathbf{F}(\mathbf{N})$ & $\mathbf{A}_{\mathbf{c}}\left(\mathbf{m m}^{\mathbf{2}}\right)$ & $\boldsymbol{f}_{\boldsymbol{c}}\left(\mathbf{N} / \mathbf{m m}^{\mathbf{2}}\right)$ \\
\hline 3 & 300 & 2500 & 0.12 \\
\hline 7 & 600 & 2600 & 0.23 \\
\hline 14 & 600 & 2605 & 0.23 \\
\hline 21 & 700 & 2500 & 0.28 \\
\hline 28 & 1100 & 2550 & 0.43 \\
\hline 56 & 1150 & 2500 & 0.46 \\
\hline
\end{tabular}

where: $\quad \mathrm{F}=$ force;

$\mathrm{A}_{\mathrm{c}}=$ cross sectional area; and

$\mathrm{f}_{\mathrm{c}}=$ compressive strength.

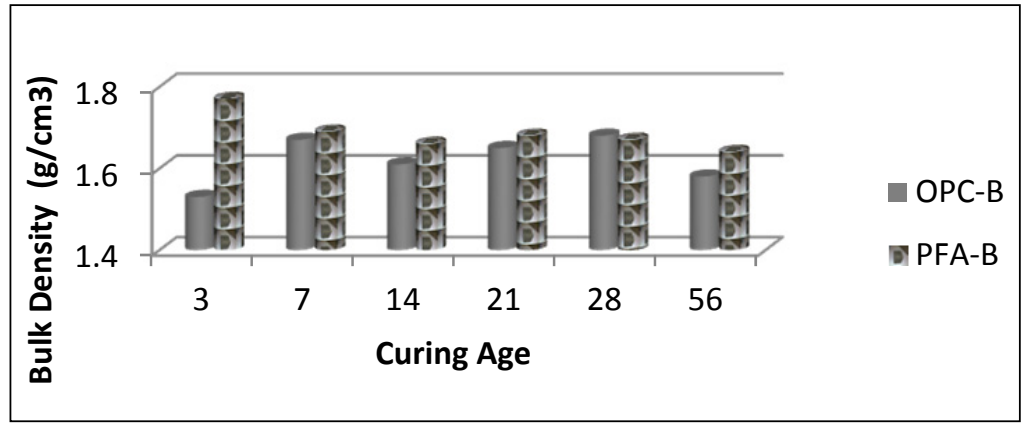

Figure 1: Relationship between bulk density and curing age. 


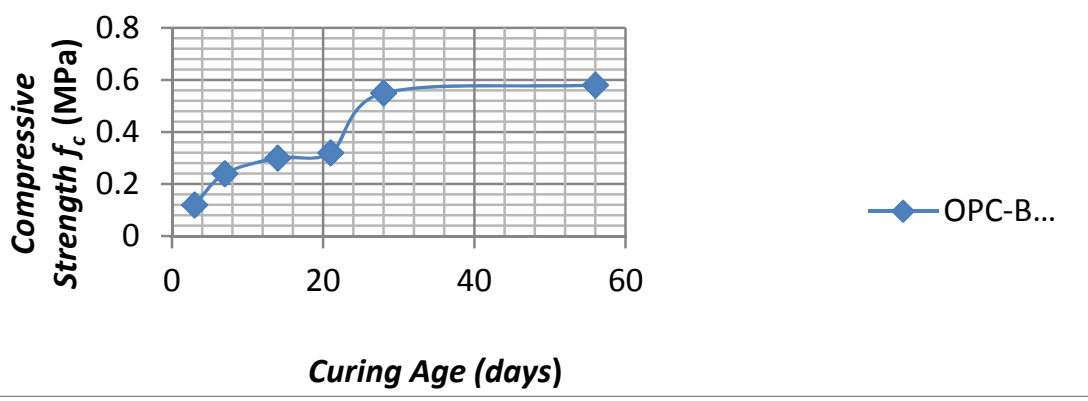

Figure 2: Graph showing the rate of strength development of OPC-B samples.

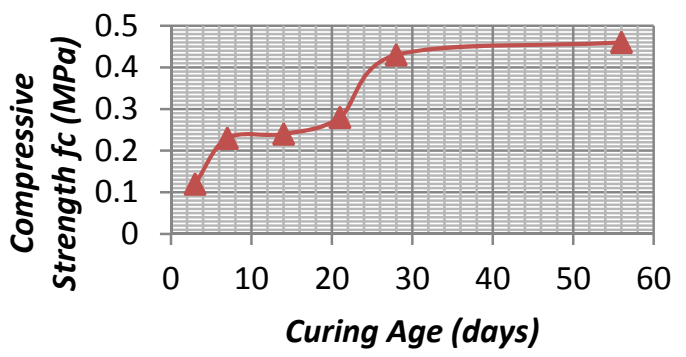

—PFA-B Samples with $5 \%$ binder content $(70 \%$ OPC $+30 \%$ PFA) \& w/c ratio of 8

\section{Curing Age (days)}

Figure 3: Graph showing the rate of strength development of PFA-B samples.

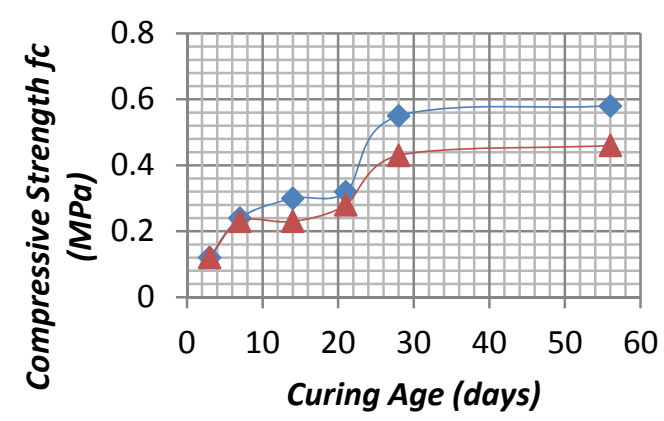

OPC-B Samples with $5 \%$ binder content $\& w / c$ of 12

Figure 4: $\quad$ Combined graph showing UCS of samples OPC-B and PFA-B. 


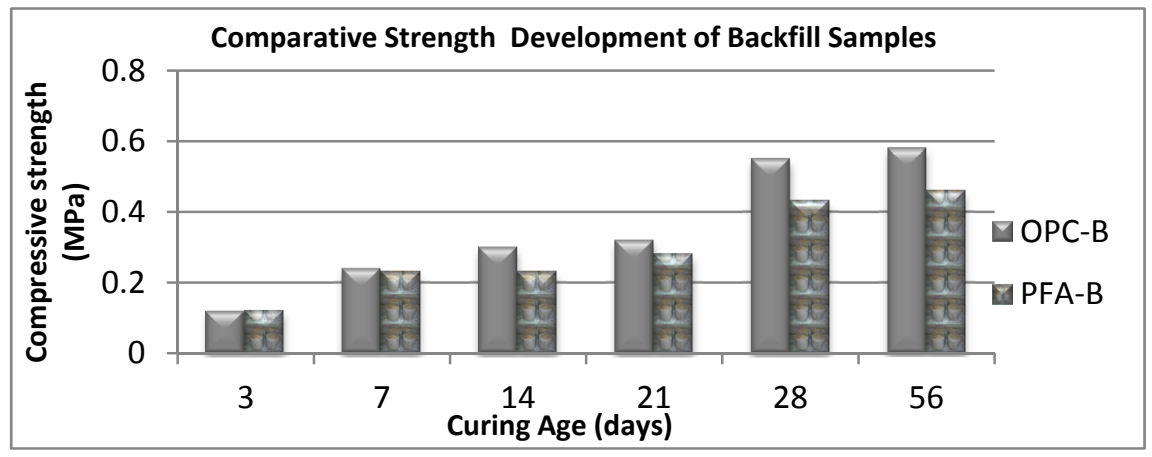

Figure 5: $\quad$ Comparative strength development of backfill samples.

\subsection{Moisture content test results}

Table 5 below shows moisture content of OPC-B and PFA-B samples over the curing ages. The graphical representations of these results are also shown in Figure 5.

Table 5: $\quad$ Moisture content of backfill samples with age.

\begin{tabular}{|c|c|c|}
\hline Curing Age (Days) & \multicolumn{2}{|c|}{ Average Moisture Content (\% weight) } \\
\hline & OPC-B (w/c=12) & PFA-B (w/c=8) \\
\hline 3 & 36.24 & 31.04 \\
\hline 7 & 35.15 & 30.00 \\
\hline 14 & 34.00 & 28.45 \\
\hline 21 & 30.56 & 27.22 \\
\hline 28 & 26.48 & 27.22 \\
\hline 56 & 20.20 & 24.00 \\
\hline
\end{tabular}

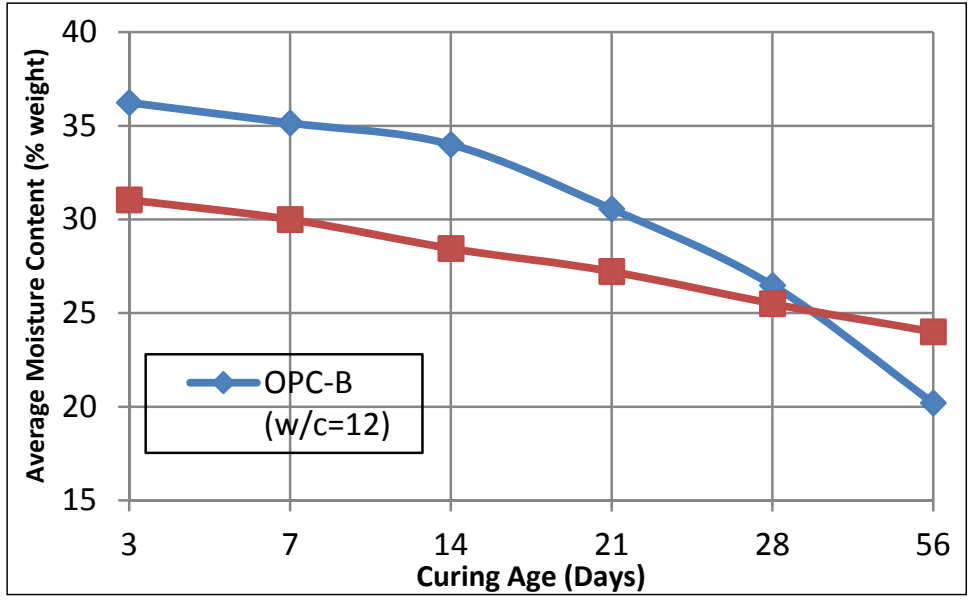

Figure 6: Moisture content of backfill samples with age. 


\subsection{Specific gravity test results}

The average specific gravity for grounded OPC-B and PFA-B samples at 56 days are 2.7 and $2.6 \mathrm{~g} / \mathrm{cm}^{3}$ respectively as obtained from the micrometrics helium pycnometer. Hence, porosity of samples can then be obtained using the moisture content and bulk density results.

\subsection{Hydraulic conductivity test results}

The PFA-B samples sheared before placement in the permeameter cell. As such, results could not be obtained for this mix. However, OPC-B samples were successfully placed into the cell without shearing and test conducted. Test results showed an average hydraulic conductivity of $3.3 \times 10^{-6} \mathrm{~cm} / \mathrm{s}$.

\section{Discussion}

\subsection{Backfill workability (consistency)}

Fresh mine backfill requires pumping underground; this explains the need for backfill to be highly workable to ensure smooth operation. This implies the volumetric water content is always higher than the quantity required for complete hydration. The flow table test measures (table 1) the workability/consistency of backfill. OPC-B samples measured $260 \mathrm{~mm}$ in flow value while PFA-B measured $215 \mathrm{~mm}$. Flow table results suggests that PDC backfill samples falls within this range and requires little modification for the water-binder ratio for the OPC-B (12) to fall within the targeted flow value. Reducing water-binder ratio is expected to match the desired consistency.

\subsection{Bulk density and moisture content}

Results obtained from the determination of bulk density indicate minimal variability over the 56 days period of testing. Values obtained ranged from 1.53 to $1.68\left(\mathrm{~g} / \mathrm{cm}^{3}\right)$ for OPC-B and 1.64 to $1.77\left(\mathrm{~g} / \mathrm{cm}^{3}\right)$ for PFA-B samples giving a maximum percentile change of $10 \%$ and $8 \%$ respectively. Expectedly, the PFAB samples were observed to be of higher density even when the volume was fairly consistent. This is apparently due to the introduction of PFA pozzolan which has been proven to hydrate at later stages of curing. In addition, the total weight of cementitious material is increased by $15 \%$ when PFA is used to replace OPC by $30 \%$.

Results obtained revealed a gradual decline in the moisture content as the day goes by for both mixes. At 56 days, moisture content of crushed OPC-B and PFA-B samples was $20.20 \%$ and $24 \%$ respectively. This is probably due to the high $\mathrm{w} / \mathrm{c}$ ratio of the mixes. Backfill mixes generally contain more than require water for hydration. This is to allow for the pumping of the mixes into the underground mine. 


\subsection{Unconfined Compressive Strength tests (UCS)}

The UCS test is generally used to measure the rate of strength development in materials. It's also a quality control measure in all industries that utilises cemented mixes. For the mining industry, the CPB backfill must satisfy minimum strength requirements before it can deployed for its operation. In general, backfill are classified based on their functional roles in the operation and their strength is directly proportional to binder content. The study showed that for roof support, minimum strength required at 28 days was $4 \mathrm{MPa}$ while that of free-standing fill and void filling, the values are in the minimum of $1 \mathrm{MPa}$ and $0.3 \mathrm{MPa}$ respectively. This classification ensures that right backfill type is applied for safe and economical mining operations.

Results from the UCS test indicate a gradual increase in strength development over the 56 days curing period for both samples. The maximum strength attained (in MPa) was 0.58 and 0.46 for OPC-B and PFA-B samples respectively. The strength gain from the initial curing age (3) to the final one (56) was $383 \%$ and $283 \%$ for OPC-B and PFA-B in that order. The higher strength observed in OPC-B is not unconnected to the OPC binder used which usually hydrates at a faster rate. Pozzolan like PFA, provide a cost cutting measure for backfill provided the quality criteria are not compromised. They hydrates fills the voids within the matrix thus, reducing permeability. This leads to strength improvement in the mix. This necessitated the introduction of PFA in the production of PFA-B mix.

Results obtained indicates that, hydration was extremely slow in these samples This is probably due to the low binder content, high water content and nature of PDC samples. For example, the OPC-B sample was made up of 5\% binder content and binder-water ratio of 12 . These possibly explain the low strength values observed in the mixes. This is an extremely weak composite mix if compared with the regular concrete design. The trend could possibly be reversed by increasing the binder content and reducing the water-binder ratio. Carrying out the later reduces permeability, increases strength and durability. However, the mix designs were in compliance with the general requirement for the production of backfill. It is then critically important for CPB mixture to have low binder content to the extent of not affecting the quality criteria of the backfill. Therefore, $5 \%$ binder content can be adjudged modest and economical. In addition, water content is usually above the quantity required for hydration. This is attributed to fluidity required to easily pump fresh backfill down into the underground mine fields.

\subsection{Hydraulic conductivity test}

Hydraulic Conductivity is one of the most important tests used to predict durability and environmental performance of CPB. The test on CPB determines the rate of leaching either by advection or diffusion. Hydraulic conductivity also depends on the nature and proportion of finer fraction of the CPB [8]. Therefore, the test enables the comprehension of rate of groundwater flow through CPB and reveals the interconnectedness of the pores. Test was carried out at 28 days 
curing age but samples (in duplicates) were completely immersed in deionised water for 7days before testing. One of the mixes, PFA-B sample was not suitable for the test because it sheared prior to placement in triaxial cell. The presence of PFA as part of the binder content coupled with the relatively high water content (w/c of 8) might have delayed full hydration of the samples.

The hydraulic conductivity tests on OPC-B samples were extremely fast. The maximum time interval between the commencement and completion of a run was $115 \mathrm{~s}$. This suggests a very porous sample. The range of values obtained varied from $3.2 \times 10^{-6} \mathrm{~cm} / \mathrm{s}$ to $3.4 \times 10^{-6} \mathrm{~cm} / \mathrm{s}$. On the average, the saturated hydraulic conductivity of OPC-B samples tested on the 28day of curing was $3.3 \times 10^{-6} \mathrm{~cm} / \mathrm{s}$. Interestingly, this result compare favourably with previous work done using mine tailings for CPB. For instance, Fall and Benzaazoua [8] reported that saturated hydraulic conductivity of CPB with tailings is in the range of $10^{-5}-10^{-6} \mathrm{~cm} / \mathrm{s}$. This result further reinforces the earlier statement that PDC backfill samples (OPC-B and PFA-B) are highly porous and are probably subject to leaching and seepage if not treated. Hence, the need to ensure their treatment (thermal desorption) before recycling (CPB) to minimise their environmental impacts especially on groundwater.

\section{Conclusions}

This study highlights the various potential utilisations of PDC, their environmental impacts and technologies available for their treatment. Emphasis was on the potential of thermally treated PDC waste as a resource material in the production of backfill for mining operations. Using pozzolan as means of reducing cost of backfill without compromising quality was also examined. The backfill samples, OPC-B and PFA-B generally showed low UCS values. Results obtained showed a UCS of $0.58 \mathrm{MPa}$ and $0.46 \mathrm{MPa}$ at 56 days curing periods, for OPC-B and PFA-B respectively. Although, the rate of strength development increased with age in both samples, the introduction of PFA in the PFA-B mix appeared to have slowed down the strength development in the early stages. Saturated hydraulic conductivity test results of $3.3 \times 10^{-6} \mathrm{~cm} / \mathrm{s}$ for OPC-B sample indicates; a highly porous matrix. The hydraulic conductivity of the PFA-B sample could not be measured on 28days owing to retard hydration traced to the PFA binder content. In the final analysis, OPC-B and PFA-B may be further considered for use as backfill for void filling or underground disposal rather than for ground support or free-standing fill applications.

Based on the results obtained from the various tests carried out, formulations OPC-B and PFA-B both appear to be candidates for use as void filling material. However, improvement is required for the scope of these wastes applications to cover ground supports and free stranding applications.

\section{References}

[1] Dhir, R.K., Cleaned oil-drill cuttings for use as filler in bituminous mixtures. Construction and Building Materials, 24(3):pp. 322-325, 2010. 
[2] Al-Ansary, M.S., Al-Tabbaa, A., Stabilisation/solidification of synthetic petroleum drill cuttings. Journal of Hazardous Materials, 141 (2):pp. 410421, 2007.

[3] Shang, H., Microwave treatment of oil-contaminated North Sea drill cuttings in a high power multimode cavity. Separation Purification Technology, 49(1): pp. 84-90, 2006.

[4] EWG, Crude Oil: the supply outlook. Energy Watch Group: EWG- Series No $3 / 2007$.

[5] Robinson, J.P., Remediation of oil-contaminated drill cuttings using continuous microwave heating. Chemical Engineering Journal, 152(23):pp. 458-463, 2009.

[6] Damone, P., and Jin, J., The use of drill cuttings for Civil Engineering applications. Department of Civil and Environmental Engineering, MSc Thesis, University College London (Unpublished).2002.

[7] Ercikdi, B., Utilization of industrial waste products as pozzolanic material in cement paste backfill of high sulphide mill tailings. Journal of Hazardous Materials, 168 (2-3):pp. 848-856, 2009.

[8] Fall, M., Benzaazoua, M., 2005. Modeling the effect of sulfate on strength development of paste backfill and binder mixture optimization. Cement and Concrete Research, 35 (2) : $301-314$.

[9] Belem, T., Benzaazoua, M., 2008. Design and Application of Underground Mine Paste Backfill Technology. Geotechnical and Geological Engineering, 26 (2):147-174. 